\title{
El Defensor Universitario. Entre la ética y la política
}

José María Aguirre Oraa

Exdefensor de la Universidad de La Rioja

En memoria de Pepelu, José Luis Alonso Martínez, exdefensor de la Universidad de Zaragoza y en agradecimiento a todos los defensores amigos del G-9 ampliado y de la CEDU.

\section{Resumen}

Este artículo recoge la ponencia que presenté en la reunión de los Defensores del G9 de Universidades realizada en la Universidad de La Rioja en junio de 2017. A modo de despedida, no sólo de la Defensoría, sino también de la Universidad, comparto algunas reflexiones acerca de la labor de los Defensores y Defensoras en la Universidad, matizadas por mi vinculación académica con el Área de Filosofía Moral.

\section{Empezando...}

Quisiera comenzar este artículo con unas palabras que escribí en un librohomenaje a Jose Luis Alonso Martínez, Pepelu para los amigos, muerto repentinamente en pleno ejercicio de su defensoría de la Universidad de Zaragoza:

Mis compañeros y yo apreciábamos en Pepelu sus diagnósticos certeros sobre la situación universitaria y social, su capacidad de escucha, su insobornable preocupación por la solidaridad y la justicia. Por eso era un Defensor de valía, un compañero entrañable, de los que dejan huella, de los que necesitamos como el respirar. Con una humanidad radiante. Irremplazable por su estatura moral y social. Cálido y cercano, sin intentar imponerse, pero sin dejar de insistir en los valores fundamentales que debemos mantener: ser Defensores de los derechos y libertades de todas las personas que forman parte del amplio y complejo mundo universitario (Aguirre Oraá, 2013, 91-92).

Por eso quisiera recordar nuestra historia práctica e intelectual, en es- 
pecial algunos textos (entre los muchos que se han elaborado en nuestros encuentros y asambleas) que pueden situar el tema que me ocupa. Nuestro último expresidente de la Conferencia Estatal de Defensores Universitarios y Defensor de la Universidad de Murcia, Pepe Palazón, expresa muy bien algunas tareas de nuestra actividad en el artículo incluido en este número, cuyo origen es una conferencia pronunciada en el IX Congreso Iberoamericano de Docencia Universitaria, celebrado en Murcia en 2016:

El Defensor Universitario no tiene, salvo algunas excepciones, capacidad ejecutiva y actúa utilizando su autoridad moral o auctoritas para solucionar conflictos, generar buenas prácticas, facilitar consensos, restituir derechos vulnerados o hacer propuestas que contribuyan a un mejor funcionamiento de las universidades. Todas las actuaciones que acabamos de nombrar, redundan en la mejora de la calidad de las universidades (Palazón, en este número).

Una de las características más generales de los defensores universitarios, tanto en el ámbito iberoamericano como en el anglosajón y en el ámbito europeo, es el uso de la mediación como estrategia para resolver conflictos entre personas. La mediación permite que conflictos entre compañeros, entre estudiantes y profesores o entre profesores y autoridades académicas se puedan resolver sin tener que recurrir a procesos judiciales o administrativos que son más lentos, más costosos y que dan lugar a soluciones impuestas".

También señalan otras perspectivas interesantes Argimiro Rojo, Defensor de la Universidad de Vigo y Eduardo Gamero, quien fue Defensor de la Universidad Pablo de Olavide, en uno de los documentos de conclusiones redactados durante el XV Encuentro Estatal de Defensores Universitarios, celebrado en Almería en 2012:

La comunidad universitaria presenta unas peculiaridades antropológicas indudables. El rasgo más característico que tradicionalmente la marca es el corporativismo de cada sector, al que se asocia un fuerte componente jerárquico interno o ínsito de cada uno de ellos. Existen escalas muy marcadas en los tres sectores de la comunidad universitaria, y especialmente en el profesorado. Pero, además, la interactuación de personas de diferentes sectores depara unas relaciones completamente asimétricas

La intervención de la Defensoría Universitaria es un factor que reequilibra esa asimetría. Esta circunstancia es un factor determinante a la hora de que las personas se animen finalmente a presentar su escrito de queja y a llevar un asunto adelante. Importa decir todo esto porque el siste- 
ma de quejas es un importante instrumento de depuración de errores, disfunciones y problemas de funcionamiento. (Rojo Salgado y Gamero Casado, 2012).

Quiero, finalmente, cerrar este apartado sobre la forma de actuar del Defensor Universitario trayendo a colación las magistrales palabras del profesor Artur Juncosa en 1996, también recordadas y citadas por extenso por Pepe Palazón en el artículo precedente, a propósito del perfil de la función de los defensores, inscrito en el siguiente triedro: "Más justicia que derecho"; "Más autoridad que poder" y "Más humanismo que burocracia" (Juncosa, 1996).

\section{Entre la ética y la política}

Cuando indico en el título de esta conferencia que el Defensor Universitario se encuentra entre la ética y la política, estoy señalando bien. Lo importante es el entre, entre las dos. El Defensor se encuentra entre una y otra, situado entre las fuerzas de gravedad de una y otra. Entre la perspectiva ética que debe defender, alentar y mantener y la perspectiva política en la que debe moverse con dignidad, con prudencia y con inteligencia. Este entre significa que no puede evadirse de su responsabilidad ética, que no puede abdicar de su mandato de defender los derechos y libertades de todos los miembros de la comunidad universitaria. Elegido democráticamente, la figura del Defensor Universitario representa fundamentalmente una instancia moral, una autoridad moral para construir éticamente el amplio terreno de las decisiones universitarias.

Y este entre significa también que el Defensor Universitario debe saber moverse en el proceloso mar de las acciones humanas para que sus recomendaciones, sus propuestas, sus mediaciones..., puedan tener una incidencia real y efectiva en la dinámica de la vida universitaria. No basta solo, a mi entender, con saber y acertar en lo que es justo y adecuado, lo cual requiere tiempo, diálogo y reflexión. Hace falta también inteligencia, audacia y prudencia para intentar que el trabajo y las propuestas del Defensor sean efectivas. Y cuando hablo de prudencia, no hablo de echar el freno para ser moderado o aparentar serlo, sino de saber cómo desarrollar nuestras actividades de manera eficaz, de manera que incida realmente en la vida universitaria. No se trata de descargar nuestra conciencia y nuestro deber. Se trata de acertar.

Evidentemente esta perspectiva que defiendo no debe suponer que van a ser aceptadas siempre nuestras propuestas, si somos prudentes e inteligentes. Nuestra historia personal como Defensores, lo hemos hablado muchas veces entre nosotros en numerosos foros, es una historia trufada 
de aciertos y de fracasos, de triunfos y de derrotas. Y aquí cada uno con su experiencia pone unos y otras en la balanza y hace una valoración. Hay que contar con autoridades académicas y poderes universitarios que no están interesados en determinadas propuestas o recomendaciones del Defensor bien porque no les parecen oportunas (y están en su derecho) o porque les cuestionan sus prácticas académicas y no están dispuestos a cambiar porque lo diga el Defensor (jsolo faltaba eso, hacerle caso al Defensor!)

Con ello entramos en el terreno siempre tenso y difícil de las relaciones entre la ética y la política, porque los principios tienen que articularse con situaciones concretas para poder clarificarlas. Y ahí juega su papel, junto a la honestidad ética, el análisis serio y la prudencia política, que no es ni miedo ni posibilismo barato, sino justeza de miras, para tratar de ver claro y articular propuestas éticas razonables. En este campo no hay certezas científicas u objetividades claras y, si las hay, suelen resultar muy peligrosas y altamente aterradoras. Se trata de perspectivas, que requieren de la interrogación y de la búsqueda. Y además creo que es difícil tener perspectivas claras, ya que el campo de la acción humana es un campo de ambigüedades, de intenciones no queridas pero creadas, de finitud humana en definitiva.

Esto nos lleva inexorablemente al desarrollo de una cultura política de la discusión y del debate que aparece como componente esencial y constitutivo de una democracia viva y real. Solo un espacio público abierto y tensional es capaz de introducir antídotos sociales y perspectivas emancipadoras frente al dominio abierto o solapado de los poderes económicos, políticos o mediáticos. La cultura viva de la discusión se autoorganiza y se expande a partir de su propio ejercicio; no se impone por decreto institucional. Se ejerce a partir de tradiciones de libertad que aseguran el ejercicio de las libertades. El filósofo Jürgen Habermas señala:

La formación democrática de la opinión y de la voluntad exige que se aseguren los derechos fundamentales. Pero tal formación depende sobre todo de una comunicación pública descentralizada, no coercitiva, no forzada y verdaderamente viva y, por tanto, de una inserción en una cultura política que en una población convierta en costumbre la discusión pública y el trato civil de unos con otros. Tal cultura democrática de la discusión exige como precio un alto grado de tolerancia incluso frente al irritante comportamiento de aquellos que se mueven en esa zona de penumbra entre la anomia y la innovación. Además, una cultura democrática de la discusión solo puede regenerarse a partir de tradiciones más o menos logradas de la libertad. No es algo que pueda organizarse. Frente a la cultura política el Estado choca con los límites de las posibilidades de intervención administrativa (Habermas, 1988, 61) 


\section{El conflicto en la existencia humana}

Deberíamos partir de una primera aproximación que puede parecer hasta banal y simple, pero que no por ello deja de ser una vieja verdad. Se trata de la constatación de que los conflictos acompañan la vida y la existencia de las personas y de las sociedades. Nuestra experiencia personal y social y nuestra memoria histórica así nos lo señalan con absoluta claridad. Las tensiones, los conflictos de pequeña o de gran intensidad han acompañado y acompañan la existencia humana y los procesos de las sociedades humanas. No se trata de ponerse tremendista y reducir a conflicto la existencia humana, sino de señalar que este se muestra presente en la vida humana. Hay conflictos personales, familiares, sociales, laborales, políticos, hasta desembocar en las guerras, el conflicto por antonomasia, por lo menos aparentemente.

Esto es así en primer lugar porque la vida del hombre no es una vida fijada, un comportamiento regulado por automatismos establecidos y fijos, sino un despliegue de las potencias y dinamismos de cada uno. En ese despliegue la persona se encuentra con otras personas con las que tiene que regular sus comportamientos. La persona, por poseer libertad de comportamiento y no tener respuestas biológicas establecidas, como los animales, debe establecer sus pautas de conducta conforme a criterios morales. A este respecto conviene subrayar que la persona humana es constitutivamente moral. En estricta lógica no existe una persona "inmoral" ni "amoral": hay morales "asesinas" y morales "benefactoras", pero nadie puede escapar de su constitución moral y situarse en el terreno "neutro" de la amoralidad. Los animales tienen un comportamiento "ajustado" instintivamente a su medio. Los hombres, en cambio, deben "ajustar" sus acciones en libertad y por lo tanto deben elegir qué hacer. Y elegir supone plantearse qué normas morales deben ser aceptadas como válidas y cuáles deben ser justificadas. Es necesario pensar, justificar, argumentar.

Como la persona no está hecha ni acabada, tiene que ir haciéndose progresivamente. Algo semejante les sucede a las sociedades: como no son realidades rígidas, también tienen que seguir haciéndose. Aquí aparecen los choques de libertades, las tensiones entre las personas, los conflictos de todo tipo. Las personas, además, tienen intereses amplísimos que quieren desarrollar o defender o imponer, por lo que en todos los ámbitos de la vida social aparecen tensiones y conflictos fruto del choque de intereses y libertades de los humanos. Es lo normal en la vida humana. No hay persona humana sin tensiones y conflictos (decía mi viejo profesor José Manzana con ironía y humor: "aquel que no tiene complejos, es un "simplejo""). "El hombre "sano" no es tanto el que ha eliminado de sí mismo las contradicciones, sino el que las utiliza y las incorpora a su trabajo", nos recuerda 
sabiamente Merleau-Ponty $(1964,286)$. No hay sociedad humana sin tensiones y conflictos porque dentro de ella hay intereses diversos y a veces muy contrapuestos y hasta antagónicos, de orden cultural, económico, y político.

Con ello entramos de lleno en la problemática del poder, de las violencias y de las posibilidades de emancipación. Toda sociedad se estructura en instituciones que desempeñan un poder de acción y de influencia, una autoridad en su ámbito. Y en esta lógica inexcusable hay un empleo de poder para estructurar esta sociedad y hasta un empleo de la violencia. Por eso en la vida humana es imprescindible y necesario reflexionar sobre la legitimidad (que no la legalidad) de la autoridad y del poder, de la violencia legítima y de las posibilidades de emancipación humana. Esta problemática es amplísima, nos llevaría muy lejos y sería una ardua y complicada tarea, pero, al menos, quisiera señalar ciertas pistas reflexivas

Ante esta realidad inexcusable de tensiones y conflictos las personas y los grupos humanos pueden adoptar grosso modo tres actitudes: la despreocupación y la banalidad, la imposición de intereses y criterios de unos contra otros, la solución dialogada y humana de los conflictos. La primera actitud consiste en cerrar los ojos a lo que sucede, practicar la política del avestruz, esperando que una mano invisible, humana o divina, solucione los conflictos por arte de magia o inhibirse conscientemente de toda realidad. Esta actitud no creo que solucione los problemas. La segunda actitud, con un gran peso histórico, consiste en imponer de manera subrepticia o palmaria los intereses y los criterios de una parte (persona, grupo, clase, nación) sobre el conjunto de los afectados. Este planteamiento tampoco soluciona los problemas a largo plazo, incluso los agrava más. La tercera actitud implica recurrir a la palabra y a la reflexión para encontrar soluciones humanas y justas a los conflictos que están planteados. Esta me parece la mejor solución posible y en este sentido muy acorde con la misión que esperamos del Defensor Universitario.

\section{Necesidad de la ética}

Todo lo dicho anteriormente tiene que ver con la ética. La ética no consiste en "plegarse" a la realidad sin más, a lo existente porque existe, a lo que impera de hecho sin más, dando encima justificación normativa a esa realidad. Porque sabemos que existe la corrupción, el narcotráfico, la violencia..., muchos fenómenos que no debieran existir. Y su mera existencia no justifica el que deban existir; más bien muchas personas coincidirían en no admitir ni justificar su existencia. La ética es fundamentalmente $y$, ante todo, otra cosa. Es propuesta de finalidades para el hombre, de anhelos de humanidad mayor para todos, de valores para un desarrollo más humano 
de las personas y de la vida social. La ética no es el campo de lo que es, de lo que se impone sin más, sino de lo que debe ser, de lo que puede ser mejor para la vida de los hombres y de las sociedades. La ética es el campo de lo que debe ser más conforme a las exigencias de la razón humana. Así lo expresaba ante Jürgen Habermas el filósofo Herbert Marcuse poco antes de morir, con toda su carga de experiencia, buscando el anclaje universal de la ética:

En la exigencia de la razón no resuena otra cosa que una vieja verdad, a saber, la exigencia de crear una organización social en la que los individuos regulen en común su vida de acuerdo con sus necesidades. [...] Cuando apelamos al derecho de la humanidad a la paz, al derecho de la humanidad a acabar con la explotación y la opresión, no se trata aquí de intereses especiales de grupo, que el mismo grupo haya definido, sino que se trata de intereses de los que se puede demostrar que constituyen un derecho universal. (Habermas, 1985, 290 y 290)

Por eso la propuesta ética postula que la ley de la fuerza no es la ley que tiene que regir la lógica de nuestras actuaciones con las otras personas, ni la de nuestras sociedades ni la de las relaciones internacionales, aunque lo sea de hecho en muchas ocasiones. Los individuos tienen que desarrollarse sin que un poder autoritario los domine. Los pueblos no pueden ser dominados por otros pueblos que tengan mayor poder político o económico o ejércitos más potentes. Esto supone una crítica y una alternativa. Por una parte, esto significa un no rotundo a cualquier estructuración piramidal y autoritaria de nuestras sociedades y de las relaciones entre las naciones; por otra, esto representa un sí al desarrollo autónomo y en libertad de los individuos y de las naciones.

Esta propuesta ética desconcierta a dos clases de personas. Por un lado, a los que razonan siempre en clave de fuerza, en clave de poder, en clave "militar", a la hora de solucionar los problemas sociales, políticos e internacionales. Por otro lado, a aquellos que aceptan sin más el orden establecido (que muchas veces no es más que el "desorden establecido" contra el que clamaba con energía Enmanuel Mounier), las desigualdades sociales (jsiempre han existido!, se dice), las injusticias de todo tipo (jmenos las que les hacen a ellos!), las dominaciones políticas. A ambos grupos de personas esta propuesta ética les "desconcierta" porque les socava el fundamento de sus planteamientos éticos corrientes y usuales, recordándoles otros principios universales que aparecen como más adecuados para inspirar la vida en común de las personas.

Esto supone reactivar lo que se debería hacer, el sentido utópico, frente a las irracionalidades de la realidad. El filósofo alemán Jürgen Habermas 
indica que cuando los manantiales utópicos se secan, se difunde un desierto de trivialidad y de degradación. Sin sentido utópico las personas y las sociedades se aletargan y se esclerotizan. Perder nuestro sentido utópico, nuestra dimensión utópica, significaría matar nuestras raíces éticas, nuestros anhelos de emancipación, nuestras propuestas de mayor humanidad y de derechos para todos, que son precisamente una de las características fundamentales del ser humano.

\section{Democracia como moral}

Como la democracia es la instauración de la libertad para todos, de la igualdad para todos, de la solidaridad para todos, la democracia debe extenderse a todos los campos de la actividad humana y no quedarse solo en el campo de lo político. Debe extenderse a lo económico, a lo social, a la cultura, a los medios de comunicación, a la relación entre géneros, etc. En este sentido hay que recuperar la perspectiva defendida por Aranguren, cuando hablaba de democracia como moral y recordaba constantemente que ese era el objetivo de una sociedad justa. La democracia no es solamente un sistema funcional de organización política, sino sobre todo la instauración social y política efectiva de los valores morales de autonomía, de respeto a la dignidad humana, de libertad, de solidaridad. Por eso Karl Marx denunció acertadamente una realidad que constantemente acecha a las sociedades "democráticas": la falacia de una organización social de ciudadanos que proclama en teoría la libertad ciudadana e instaura en la práctica el dominio de unos pocos sobre la gran mayoría por su posesión de los medios de producción, por su posesión de los grandes medios económicos de una sociedad.

Consecuentemente hay que alumbrar y configurar un concepto amplio y rico de democracia. Creo en este sentido que la calidad moral de una sociedad democrática se pueda apreciar en su atención real al desarrollo de todos, pero sobre todo a aquellos que están en situación de indefensión, de pobreza, de marginalidad. No se trata únicamente de atención social, se trata sobre todo de desarrollo de una autonomía personal y social que debe pasar del ámbito político a los restantes ámbitos de la vida de una sociedad. Como nos recuerda Jean Ladrière, presidente durante muchos años del Instituto Superior de Filosofía de la Universidad Católica de Lovaina:

El sentido de la acción voluntaria es asegurar progresivamente la realización [de su propia esencia] y, en definitiva, hacer existir un reino de libertad, donde la voluntad sea verdaderamente reconciliada consigo misma. Reconciliación que no es, por lo demás, posible más que en una reciprocidad incondicional de las voluntades, en el reconocimiento mutuo sin reservas de las voluntades libres entre sí, dicho de modo conciso 
También José Luis López Aranguren reitera en distintos escritos que la democracia tiene que inventarse constantemente, que no está nunca establecida ni acabada. Hay que concebir la democracia como una tarea moral, como una aspiración, como un ideal. Al igual que el ethos tiene que crearse y construirse en cada hombre, la democracia es una especie de ethos social que necesita de constante revisión, crítica y estímulo. El ethos personal se va creando por los actos realizados y por los hábitos adquiridos. La democracia como ethos social también tiene que irse reinventando, reconquistando, a través de los actos y hábitos comunes a los ciudadanos, es una tarea personal y colectiva que no tiene fin, como tampoco tiene fin la creación del ethos personal. Para que se realice la democracia, se requiere una voluntad moral en favor de la misma, pues con mucha facilidad el hombreciudadano se cansa de la carga de la libertad política, se aliena, se enajena en sus diversiones o negocios, en su vida privada consumista, materialista y egoísta, se despolitiza y cede su responsabilidad político-moral a otros (a la tecnocracia) a cambio del orden y de la seguridad.

La democracia, antes y más profundamente que un sistema de gobierno, es un sistema de valores, que demanda una reeducación político-moral. Cito las palabras de Aranguren:

Junto a la concepción cínica, trágica y dramática, cabe una concepción utópica de la política: concepción plenamente moral, por verdaderamente democrática, de la política: concepción de la democracia como el final de un camino que nunca acabaremos de recorrer y que hemos de recorrer, siempre adelante; democracia como modo de ser de todos los ciudadanos. Esta concepción, no por ser utópica nos consiente "arrellanarnos confortablemente en el sillón de la utopía", sino que, al contrario, nos demanda seguir luchando incesantemente por ella. La utopía es el espíritu de la "letra" política y, como tal, tiene que penetrar de sentido a esta. Ninguna democracia establecida es plenamente democrática (López Aranguren, 1996, 555) ${ }^{1}$.

La democracia es un ideal alcanzable y nunca alcanzado, marcha de la democracia y democracia en marcha, esfuerzo conjunto por la plena democratización. La democracia nunca puede dejar de ser lucha por la democracia, pues en caso contrario se destruiría a sí misma. Por eso ser demócrata

1 En su ensayo "Utopía y libertad", el mismo Aranguren escribe: "La utopía estrictamente dicha inventa, como dijo Ortega, ahormar la realidad del pensamiento, en vez de ajustar el pensamiento a la realidad y sustituir esta por una imagen suya forjada por la fantasía" (López Aranguren, 1984, 23). 
es un problema de educación, no de educación elitista o teórica, sino de educación moral inserta en la praxis, unida al ejercicio efectivo de la democracia. La democracia solo se aprende practicándola. Lo que hace falta es querer practicarla, es decir, quererla. Esta voluntad de participación constituye un quehacer serio, digno del hombre y apasionante.

\section{6. Ética y política}

El hombre no solo es constitutivamente moral, sino también político. La dimensión política del hombre (la lucha por la democracia a todos los niveles) es parte de la dimensión moral que le es constitutiva (la creación de un êthos). Por ello, aun reconociendo la autonomía relativa de lo político, queda la labor de precisar en qué sentido contribuye lo político a encaminar a los hombres hacia su destino ético. No hay realidad política más que en la medida en que hay una vida colectiva y en que se afirma la necesidad de una mediación apropiada entre esta vida colectiva y las finalidades éticas. Como toda actividad humana está condicionada por la vida colectiva, hay una incidencia política en toda actividad.

Pero esto no significa de ningún modo que todo sea, aunque fuera en última instancia, de naturaleza política. Esto significa que la acción política contribuye a determinar las condiciones, más o menos favorables, en las que las diversas actividades humanas, cada una según su orden propio, podrán desarrollarse. Y como cada orden de actividad plantea problemas éticos, hay una contribución indirecta de lo político a la vida ética. Por ello subsiste una relativa independencia entre vida ética, al nivel de la acción individual, y vida política: la más grande sublimidad ética es incluso posible en las circunstancias políticas más desastrosas desde el punto de vista ético.

Sin embargo, el problema principal no se sitúa al nivel de esta incidencia indirecta de lo político; se plantea a propósito del orden político mismo. ¿Cuál es el contenido ético de este orden? Conviene resaltar que de suyo lo político está ordenado a un fin ético. Por consiguiente, en la medida en que sea capaz de remontar sus gravedades, lo político está llamado a hacer existir una cierta cualidad que solo puede hacerse realidad por medio de él. La especificidad de esta cualidad se debe a la situación mediadora de lo político. Lo que está en juego es la vida colectiva en cuanto tal, es decir las relaciones humanas en cuanto mediatas. La misión de lo político es llevar estas relaciones a un nivel ético, al precio de transformaciones apropiadas. Formalmente, este nivel ético puede ser definido como un modo de relaciones en el que cada uno es verdaderamente tratado como fin para cada uno de los otros. Concretamente la cualidad ética de la vida colectiva representa una exigencia que no puede ser encerrada en una fórmula precisa, que pre- 
cisamente por ello no puede ser planteada más que como un horizonte de acción. En cada momento histórico, en función de los desarrollos del saber, de los medios, de los recursos, de las posibilidades institucionales, se puede ver cómo se precisa esta exigencia en proyectos determinados, susceptibles de orientar efectivamente la acción.

La vida política es siempre, en consecuencia, un lugar de tensión. Por sí misma no es todavía la vida ética, pero ella toma su sentido de su ordenación a esta vida. La vida política es, por tanto, un campo de realización de la ética, pero no el ámbito entero de su concretización. Pues, aunque todas las fuerzas de la existencia pasan por una mediación de la vida colectiva, hay que insistir en que no hay coincidencia, recubrimiento, entre la vida colectiva y todas las demás formas de la existencia. El carácter «extraño" y específico de lo político radica en que constituye en cierto sentido una doble mediación. Por una parte, es mediación entre la «naturaleza social" y la exigencia ética de la reciprocidad de las conciencias. Por otra parte, en cuanto mediatiza éticamente la vida colectiva, afecta indirectamente a los otros ámbitos en que el destino ético del hombre está en juego.

Esto es lo que explica la importancia de la política, y también lo que marca sus límites. Yo lo diría con palabras del filósofo Jacques Derrida. La democracia pertenece al campo de la promesa, de la tarea, del porvenir, de la esperanza y no al campo de la posesión, del control, del adueñamiento

Porque la democracia sigue estando por venir, esa es su esencia en cuanto sigue estando: no solo seguirá siendo indefinidamente perfectible, y en consecuencia siempre insuficiente y futura, sino que, al pertenecer al tiempo de la promesa, seguirá estando siempre, en cada uno de sus tiempos futuros, por venir; incluso cuando hay democracia, esta no existe, no está jamás presente, sigue siendo el tema de un concepto no presentable. ¿Es posible abrirse al "ven" de una cierta democracia que no sea ya un insulto a la amistad que hemos intentado pensar más allá del esquema homofraternal y falogocéntrico? ¿Cuándo estaremos preparados para una experiencia de la libertad y de la igualdad que haga la prueba respetuosa de esa amistad y que se ajusta por fin, justa más allá del derecho, es decir, que esté a la medida de su desmesura? ¡Oh, mis amigos demócratas ...! (Derrida, 1998, 338).

La política sin la ética puede ser ciega y la ética sin la política terriblemente ineficaz, sin manos. Encontrar una articulación dialéctica y constante entre ambas supone siempre un reto para el pensamiento y también para la acción humana. Porque la democracia en su sentido genuino y radical, la soberanía de los ciudadanos, el poder popular real, es fundamentalmente un horizonte abierto, una perspectiva de acción y construcción, y no 
una realidad hecha y consolidada. La democracia siempre es una aspiración de futuro, un anhelo jamás satisfecho de implantación de la justicia.

\section{Finalizando...}

Me gustaría terminar con unos versos, que creo que indican bien el humus vital en el que surge una conciencia ética y su horizonte emancipador y nos incitan a pensar y a actuar con perspectiva y dinamismo emancipadores. Los primeros versos son de Gabriel Aresti (1995, 194-197), un poeta vasco muerto en plena juventud, que grita el deber sagrado de respetar la palabra humana, toda palabra humana, el pensamiento del hombre, para que pueda en libertad comprender el mundo y su propia existencia y rehacerlos:

Ez zazue tapa
gizonaren ahoa
Defiendi dadin.
Hainbeste bidegabe
egin zaio
azken ehun mila urte honetan...
Baina ez zazue,
baina ez zazue,
baina ez zazue,
ez zazue tapa
gizonaren ahoa.
Hicaz
balia dadin,
hicaz
zerbica dadin.
Honela kompreni
dezazuen
mundura.
Ez,
ez zazue tapa
gizonaren ahoa.

\author{
No le tapéis \\ la boca al hombre. \\ Que se defienda. \\ Se le ha hecho \\ tanta injusticia \\ en estos últimos cien mil años... \\ Pero no le tapéis, \\ pero no le tapéis, \\ pero no le tapéis, \\ no le tapéis \\ la boca al hombre \\ Para que se valga \\ de la palabra, \\ para que se sirva \\ de la palabra. \\ Para que así \\ comprendáis \\ para qué nace al mundo \\ No, \\ no le tapéis \\ la boca al hombre.
}

Los segundos son los versos de una célebre canción latinoamericana, escritos por León Gieco y cantados por Mercedes Sosa, y nos hablan de la solidaridad necesaria para desarrollar una conciencia y una praxis emancipadoras: 
Solo le pido a Dios que el dolor no me sea indiferente, que la reseca muerte no me encuentre, vacía y sola sin haber hecho lo suficiente.

Solo le pido a Dios que lo injusto no me sea indiferente, que no me abofeteen la otra mejilla, después de que una garra me arañó esta suerte.

Solo le pido a Dios que la guerra no me sea indiferente, es un monstruo grande y pisa fuerte toda la pobre inocencia de la gente.

Solo le pido a Dios que el engaño no me sea indiferente, si un traidor puede más que unos cuantos, que esos cuantos no lo olviden fácilmente.

Solo le pido a Dios que el futuro no me sea indiferente, desahuciado está el que tiene que marcharse a vivir una cultura diferente.

Solo le pido a Dios que la guerra no me sea indiferente, es un monstruo grande y pisa fuerte toda la pobre inocencia de la gente.

Los Defensores Universitarios debemos estar al servicio de todas las personas de la comunidad universitaria, para dar voz y expresión a sus quejas y deseos y para contribuir a la solidaridad y la justicia en el ámbito universitario. Noble tarea en la que debemos esforzarnos con la ilusión de los que mantienen en su corazón y en su mente la esperanza humana en una vida digna para todos. Esta llama no la debemos dejar apagar en nuestra actividad.

\section{Bibliografía citada}

Aguirre OraÁ, J. M. (2013). "Pepelu, Defensor Universitario". En AA. VV., Recordando a Pepelu. Zaragoza: Publicaciones de la Universidad de Zaragoza, pp. 89-95.

AREsti, G. (1995). Euskal Harria. Donosti: Editoral Susa.

DERRIDA, J. (1998). Políticas de la amistad. Madrid: Trotta.

Juncosa, A. (1996). "Reflexiones sobre la figura y función del Síndic de Greuges a partir de una experiencia personal". Comunicación presentada al I Encuentro Estatal de Defensores de la Comunidad Universitaria, Castellón, 19 y 20 de septiembre, 1996. Disponible online: http://cedu.es/images/otros_documentos/conferencias/Juncosa_1996_09. pdf (último acceso: 1 de diciembre de 2017).

Habermas, J. (1985). Perfiles filosófico-políticos. Madrid: Taurus. 
HABERMAS, J. (1988). Ensayos políticos. Barcelona: Península.

LADRIÈRE, J. (1977). Les enjeux de la rationalité. Paris: Aubier-Unesco.

López Aranguren, J. L. (1984). "Utopía y libertad", Revista de Occidente, 33-34, pp. 27-36.

López Aranguren, J. L. (1996). La democracia establecida. En Obras Completas. Vol. 5. Madrid: Trotta.

Merleau-Ponty, M. (1964). Signos. Barcelona: Seix Barral.

Rojo Salgado, A. y Gamero Casado, E. (Coord.). (2012). "Mesa de trabajo 2. La defensoría universitaria como órgano necesario, tanto más en tiempos de crisis", Conclusiones del XV Encuentro Estatal de Defensores Universitarios, Almería 19 a 21 de septiembre de 2012. Disponible online en: http://cedu.es/images/encuentros/estatales/XVEncuentro/15. mesa2.pdf (último acceso 1 de diciembre de 2017). 